\title{
Levantamento dos recursos hídricos em propriedades de transição agroecológica
}

\author{
Wilson Dias Gondim Junior ${ }^{1}$, Thiago do Nascimento Coaracy ${ }^{2}$, Silvania Maria de Souza Gomes ${ }^{3}$ \\ Universidade Federal da Paraíba; ${ }^{1}$ wilsonjunior58@gmail.com; ${ }^{2}$ thiago.coaracy@gmail.com; \\ 3 silvania.ufpb@yahoo.com.br.
}

\begin{abstract}
RESUMO: Esse relato de experiência veio através do projeto intitulado "ações educativas na qualidade da água para fins de irrigação na produção agroecológica", por meio do projeto de responsabilidade social regido pela Universidade Federal da Paraíba - UFPB campus III, Bananeiras. O estudo foi realizado objetivando identificar quais são os tipos de captação de água para fins de irrigação e quais tipos de sistema de irrigação usado nas propriedades, onde foi avaliado 13 propriedades das cidades de Serraria e Solânea na Paraíba, que participam da feira agroecológica organizada em Serraria pela FAF'S (Feira da Agricultura Familiar de Serraria), e Solânea pelo Eco Borborema (Associação dos Agricultores e Agricultoras Agroecológica do Compartimento da Borborema). Os dados foram colhidos através de visitas metodológicas de travessia nas propriedades nos dois municípios, com a elaboração de um questionário rápido adaptado do IRPAA (Instituto Regional da Pequena Agropecuária Apropriada). Com tudo apesar da boa precipitação media anual de chuva, os resultados demonstram que os agricultores possuem dificuldade para formas de armazenamento e sistema de água, e consequentemente sofrendo nas épocas de estiagem. É de grande importância para agricultura atividades de base agroecológica relacionadas ao manejo adequado dos recursos hídricos.
\end{abstract}

PALAVRAS-CHAVE: Agroecologia; Diagnóstico; Tecnologias de armazenamento.

\section{CONTEXTO}

A água é um bem importante à vida dotada de valor econômico, exerce seu ciclo global a partir das precipitações, voltando para a atmosfera através da evaporação de corpos de água e transpiração dos vegetais. Hoje em dia, a função da irrigação na agricultura Brasileira não é, apenas, fornecer água para as culturas, mas atua também como importante instrumento na elevação da produção e produtividade com reflexos na rentabilidade para o ser humano do campo. A problemática que persiste ainda hoje é resolver, o problema de abastecimento de água de uma região, principalmente no campo (GAMBARRA, 2017).

Nas últimas décadas, o homem erroneamente pensou o desenvolvimento como sinônimo de crescimento econômico, permanente e ilimitado (CAPORAL e COSTABEBER, 2006), o mesmo ocorre com o uso da água. Dessa maneira, com a ideia de aumentar o estoque de alimentos, a revolução verde permitiu uma produção intensa de produtos com o uso de máquinas, insumos e sementes selecionadas, trazendo consigo a instabilização dos ecossistemas com o uso em grande escala de agrotóxicos, insumos agrícolas, maquinários, a prática da monocultura com simplificação dos sistemas, degradação dos solos antes agricultáveis e até mesmo o avanço das fronteiras agrícolas, colocando em risco a qualidade da água para fins de irrigação e consequentemente a saúde humana (SHIVA, 2009). Além de consumir grandes quantidades de água doce no processo produtivo, problemas de contaminação do solo e dos mananciais hídricos são frequentemente ocasionados pela adoção de práticas agrícolas incompatíveis com a capacidade suporte do ambiente.

Um dos aspectos mais importantes da produção de base agroecológica além da sustentabilidade na produção, é a qualidade do alimento produzido, estando diretamente relacionados com a qualidade da água utilizada nas irrigações, que de acordo Mesquita et al. (2015) estando essa qualidade fora dos padrões normais estabelecidos pela legislação, comprometendo o alimento produzido, danifica o sistema de irrigação, além da degradação do ambiente (VASCONCELOS et al., 2013).

Portanto a agroecologia surge como alternativa de produção com práticas e tecnologias que garantam a sustentabilidade na produção através da integração de princípios agronômicos, socioeconômico e ecológicos, e uma visão de conservação e equilíbrio da biodiversidade, do solo, da água, dos nutrientes e outros organismos existentes no local (ALTIERI, 2004). Dessa forma o objetivo foi diagnosticar os sistemas de captação e armazenamento de água em propriedades em transição agroecológica no Brejo Paraibano, para posterior análise laboratorial, avaliação dos parâmetros da água e execução de estratégicas alternativas com base agroecológica.

\section{DESCRIÇÃO DA EXPERIÊNCIA}

Essa pesquisa foi realizada na região do Brejo Paraibano situado próximo ao litoral, apresentando clima que varia de tropical a úmido e semiúmido, com chuvas mais frequentes de março a julho às quais variam de $2000 \mathrm{~mm}$ a 800mm , apresentando comportamento pluviométrico semelhantes (COSTA et al., 2015). Na (figura 1) demonstra a precipitação média anual de 2018 nas microrregiões, onde o Brejo apresentou $886.2 \mathrm{~mm}$ de chuva. Entre as cidades de Serraria e Solânea, chegando a 700m de altitude em relação ao nível do mar (Francisco et al.,2014) observa-se que os menores 
GONDIM JUNIOR, W. D. et al. Levantamento dos recursos hídricos em propriedades de transição agroecológica. In: II Congresso Paraibano de Agroecologia \& IV Exposição Tecnológica, 2019. Anais... Caderno Verde de Agroecologia e Desenvolvimento Sustentável, Pombal, v. 9, n.7, e-7042, 2019.

valores de temperatura estão nas áreas de altitudes mais elevadas, destacando-se, assim, a microrregião do Brejo e grande parte do Planalto da Borborema.

Figura 1: Precipitação média das regiões pluviométricas do estado da Paraíba no ano de 2018.

\section{Meteorologia - Chuvas - AESA}

\begin{tabular}{|c|c|c|c|c|c|}
\hline Regiaso pluviometrica & Observ. (mm) & climat (mm) & Desvio $(\%)$ & Desvio (mm) & $N^{\circ}$ de Postos \\
\hline Litoral & 1363.6 & 1573.2 & -13.3 & -209.6 & 26 \\
\hline Alto Sertão & 918.6 & 886.8 & 3.6 & 31.8 & 46 \\
\hline Brejo & 886.2 & 1096.1 & -19.1 & -209.9 & 30 \\
\hline Sertão & 777.4 & 757.2 & 2.7 & 20.2 & 53 \\
\hline Agreste & 661.3 & 751.6 & -12 & -90.3 & 44 \\
\hline Cariri/Curimataú & 469.8 & 498.8 & -5.8 & -29 & 59 \\
\hline
\end{tabular}

Fonte: AESA (Agência Executiva de Gestão das Águas do Estado da Paraíba).

Inicialmente foi feito visitas nas feiras agroecológicas de Serraria e Solânea, para dialogar com os comerciantes e representantes do sindicato rural que apoiam as feiras, exercendo o papel participativo e para a construção de vínculos, vivenciar e compreender a rotina dos produtores na feira. Também houve a participação em reuniões das feiras agroecológicas a fim de apresentar o projeto e relacionar com as necessidades dos agricultores. Através dessa aproximação cuidadosa, não invasiva e respeitosa, foi conquistando a confiança, onde possibilitou que os agricultores aceitassem as visitas que foram realizadas no período de Agosto de 2019.

\section{RESULTADOS}

Foram visitadas 13 propriedades, na qual 9 fazem parte do município de Serraria, todos localizadas na comunidade do sítio Matinhas, e 4 do município de Solânea, localizados na comunidade sítio Gruta de Santa Tereza (2 propriedades) e sítio Lages (2 propriedades). Os dados foram coletados através de visitas metodológicas de travessia nas propriedades nos dois municípios, com a elaboração de um questionário rápido adaptado ao IRPAA (Instituto Regional da Pequena Agropecuária Apropriada), onde juntamente com o agricultor, apresentava todas as dependências da propriedade, enquanto se fazia o levantamento dos recursos hídricos.

Com diagnóstico realizado, foram identificados os seguintes resultados: Os principais tipos de captação de água para irrigação foram o barreiro (Figura 2), onde 6 propriedades utilizam esse meio para captação, em seguida o açude em 2 propriedade, barragem em 2, poço e cacimba (Figura 3) ambas em 1 propriedade.

Figura 2: Barreiro no sítio Matinhas - Serraria.

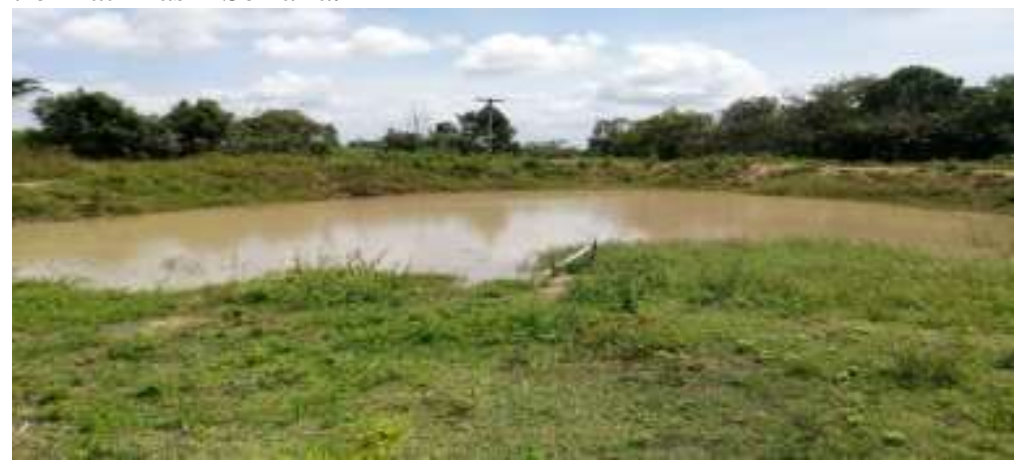

Figura 3: Cacimba e Poço no sítio Lages - Solânea.

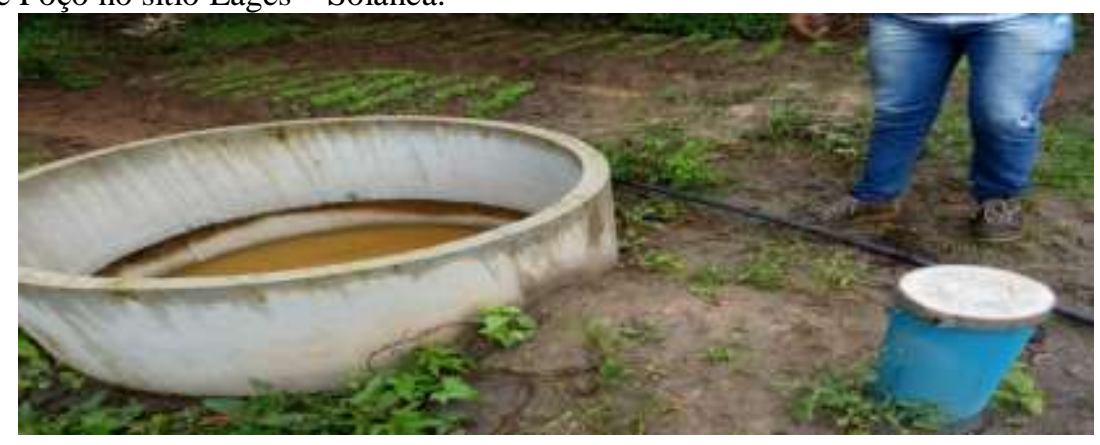


GONDIM JUNIOR, W. D. et al. Levantamento dos recursos hídricos em propriedades de transição agroecológica. In: II Congresso Paraibano de Agroecologia \& IV Exposição Tecnológica, 2019. Anais... Caderno Verde de Agroecologia e Desenvolvimento Sustentável, Pombal, v. 9, n.7, e-7042, 2019.

Já os principais tipos de sistema de irrigação utilizados pelos agricultores foram a mangueira onde 3 propriedades usam esse método, regador foram em 2 propriedades, aspersor e irrigador ambas em 1 propriedade cada e 2 não utilizam sistema de irrigação. Apesar de historicamente o brejo Paraibano apresentar um maior índice pluviométrico, em comparação com as demais microrregiões que compõem o estado da Paraíba, vem apresentando nos últimos anos estações chuvosas irregulares, com baixa precipitação média anual resultando em diminuição dos reservatórios hídricos que disponibilizam água para região (COSTA et al., 2015).

Com a obtenção dos resultados, é notada a necessidade de trabalhos que venham possibilitar a adoção correta das tecnologias de armazenamento da água e sistema de irrigação. Esses dados serviram de base para melhores tomadas de decisão, onde estratégias alternativas de baixo custo serão trabalhadas juntamente com os agricultores nas propriedades de transição agroecológica. Essas ações educativas e de conscientização geram conhecimento e para o manejo da água em todo processo produtivo de base agroecológica.

\section{CONCLUSÃO}

Apesar da boa precipitação media anual de chuva, é notório o conhecimento quanto à necessidade de se preservar a água. Além disso, compreender a qualidade nas condições higiênico-sanitárias dos alimentos produzidos, principalmente, das hortaliças as quais são constantemente consumidas cruas ou mal lavadas, faz com que o ser humano do campo cada vez mais se preocupe com a qualidade da água para fins de irrigação. Demonstrando que é essencial possuir boas formas de armazenamento e sistema de água. Dessa forma a agroecologia urge como ferramenta primordial para transformar, melhorar a qualidade de vida e manejo adequado dos recursos hídricos. Por fim os resultados apresentados irão gerar melhores ações específicas e estratégias para a qualidade da água e armazenamento.

\section{REFERÊNCIAS}

ALTIERI, M. Agroecologia: a dinâmica produtiva da agricultura sustentável. 5. ed. Porto Alegre: UFRGS, 2008.120 p. Disponível em: < http://www.reformaagrariaemdados.org.br/sites/default/files/Agroecologia\%20-\%20A\%20din\%C3\% A2mica\%20produtiva\%20da\%20agricultura\%20sustent $\%$ C3\%A1vel\%20-\%20Miguel\%20Altieri\%20\%20 Editora\%20 UFRGS,\%202008.pdf>. Acesso em: 11 set. 2019.

CAPORAL, F. R.; COSTABEBER, J. A. Segurança alimentar e agricultura sustentável: uma perspectiva agroecológica. Nov. 2006, p.14. Disponível em: <http://plataforma.cpacp.embrapa.br/mostrar_pdf.php?search=106>. Acesso em: 03 set. 2019.

COSTA, A. de S et al. Estudo do clima na região do brejo paraibano utilizando técnicas de séries temporais para previsão com o modelo Sarima. Gaia Scientia, João Pessoa, v.9, n.1, 2015, p.127-133. Disponível em: <https://periodicos.ufpb.br/ojs2/index.php/gaia/article/view/27622>. Acesso em: 03 set. 2019.

FRANCISCO, Paulo Roberto Megna; SANTOS, Djail. Climatologia do Estado da Paraíba. Campina Grande: EDUFCG, 2017, p.79. Disponível em: <https://portal.insa.gov.br/images/acervo-livros/Climatologia\%20 do\%20 Estado\%20da\%20Paraiba\%20editora.pdf>. Acesso em: 03 set. 2019.

GAMBARRA, Mayk Douglas Vilar. Proposta para integração do canal do eixo norte da transposição do rio são francisco com o sertão paraibano a partir da linha adutora COREMAS/SABUGI. 2017. 52 f. TCC (Graduação) Curso de Bacharelado em Engenharia Civil, UEPB, Araruna, 2017. Disponível em: <http://dspace.bc.uepb.edu.br/ jspui/handle/123456789/14988?mode=full>. Acesso em: 03 set. 2019.

MESQUITA, D. R et al. Ocorrência de parasitos em alface crespa (Lactuca sativa L.) em hortas comunitárias de Teresina, Piauí, Brasil. Revista Patologia Tropical, Goiânia, v. 44, n. 1, 2015, p. 67-76. Disponível em: <https://revistas.ufg.br/iptsp/article/download/34802/18393/>. Acesso em: 03 set. 2019.

PARAÍBA. Agência Executiva de Gestão das Águas. Governo da Paraíba. Precipitação média das regiões pluviométricas no estado da Paraíba. 2018. Disponível em: <http://www.aesa.pb.gov.br/aesa-website/meteorologiachuvas/?formdate=2019-09-09\&produto=regiao_pluviometrica\&periodo=anual $>$. Acesso em: 05 set. 2019.

RIBEIRO, Tamara Gurgel do Amaral. Interação Dialógica nas ações de Extensão Universitária na Temática Meio Ambiente. 2019. 103 f. Dissertação (Mestrado) - Curso de Mestre em Desenvolvimento, Tecnologias e Sociedade., Pós- Graduação em Desenvolvimento, Tecnologias e Sociedade, Universidade Federal de Itajubá, Itajubá, 2019. Cap. 4. Disponível em: <https://repositorio.unifei.edu.br/xmlui/handle/123456789/1919>. Acesso em: 03 set. 2019.

SHIVA, Vandana. Monoculturas da mente: Perspectivas da biodiversidade e da biotecnologia. São Paulo: Gaia, 2003. $240 \mathrm{p}$. 
GONDIM JUNIOR, W. D. et al. Levantamento dos recursos hídricos em propriedades de transição agroecológica. In: II Congresso Paraibano de Agroecologia \& IV Exposição Tecnológica, 2019. Anais... Caderno Verde de Agroecologia e Desenvolvimento Sustentável, Pombal, v. 9, n.7, e-7042, 2019.

VASCONCELOS, Rochele Sheila et al. Qualidade da água utilizada para irrigação na extensão da microbacia do baixo acaraú. Revista Brasileira de Agricultura Irrigada, Fortaleza, v. 3, n. 1, p.30-38, maio 2009. Disponível em: <https://www.researchgate.net/publication/271037193_Qualidade_da_agua_utilizada_para_irrigacao_na_extensao_da_ microbacia_do_Baixo_Acarau>. Acesso em: 03 set. 2019.

\section{AGRADECIMENTOS}

Apoio financeiro: Fundação de Apoio à Pesquisa do Estado da Paraíba - FAPESQ. 